\title{
Nigerian Pidgin English: A Cultural Universal for National Communication and Policy Enactment
}

\author{
Beryl Ehondor \\ School of Media \& Communication, Pan-Atlantic University, Lagos, Nigeria \\ beryl.ehondor@pau.edu.ng
}

\begin{abstract}
Recurrent ethnic conflicts and political strife are threats to national unity and pride. Some argue, this phenomenon is related to the impact of prior Western dominance, globalisation and neo-colonialism. As panacea, this paper leans on Kwasi Wiredu's proposition of Language, a Cultural Universal, as essential for intercultural and national communication. The paper, using discourse analysis argues that the Nigeria Pidgin English Language has a unifying potential for Nigeria. Nigerian Pidgin speaking is currently more popular compared to the 3 regional languages, Hausa, Igbo, Yoruba, and English language. This proposition further explored Spolsky's National Language Policy Theory. It concludes that Nigeria's multi-ethnic reality and antecedents' challenges be resolved by the pragmatic positivist approach of language unification. Recommendations include a review of the National communication policy, creation of language policy, declaration that Nigerian Pidgin be officially added to the list of languages for National Communication, in the interest of National Unity.
\end{abstract}

Keywords: Spolsky's Theory, National Communication Policy, Cultural Universal, Nigerian Pidgin English

DOI: $10.7176 / \mathrm{JPCR} / 50-09$

Publication date:November $30^{\text {th }} 2020$

\section{Introduction}

Africa and indeed Nigeria are still in the dilemma of the definition of self, the problem of identity, aggravated by the impact of British intrusion and amalgamation of different regions and ethnic groups to form the Nigerian state. With a concocted, forced identity, Nigeria continues to struggle to remain together, having controversies over what 'really' connects all the citizens.

There is an assumption that the division in the country is tied to the fact that many different ethnic groups were lumped together without a buy-in. Still, since language has a unifying potential, especially for African communities, then a drive for a common language is imperative. A common language is essential because when human persons gather, they communicate, they talk, express feelings and opinions, requiring a language to do the same. A language frames the mindset pulls down walls of resistance or conflicting philosophies and eases a unified purpose within the communication.

In contemporary times of global and intercultural relations, there is a myriad of incentive for a person to learn a contact language beyond his mother tongue (Davydov, Shapoval, \& Weber, 2018), reasons including business, social networking, politics etc. Selten \& Pool (1991) in Davydov et al. (2018) further argues that the gross communicative benefits a person is positively correlated with the number of persons he communicates with and sharing at least a common language. This language potential directly impacts business and all aspects of living, ease inter-relations and communicativity.

So as a pragmatic panacea, there have been several calls for the Nigerian Pidgin English to be adopted as lingua franca in Nigeria and virtually the language of National communication to facilitate effective communication and peace in Nigeria. The Nigerian Pidgin is widespread and spoken throughout the country (Ifechelobi \& Ifechelobi, 2015), as should a national (indigenous) language, thus necessitating a National Language Policy.

A national language policy is inspired by the pursuit to 'minimise internal differences \& maximise external ones'. However, to minimise internal differences, the ideal national language policy purposes that all citizens of the nation speaking the same language (McConville, 2016). In recognition of the impact of a language several countries have made a case for implementation of a National language policy (Bruen, 2013), (Albury, 2015), (McConville, 2016), (East, Chung, \& Arkinstall, 2012) (Gao, 2017). Nigeria also has a gap in this regard, as it has no language policy in Nigeria despite calls for it plus a language planning (Ogunmodimu, 2015) (East, Chung, \& Arkinstall, 2012), However, in an attempt at a 'balanced' approach, the government via the National communication policy carries that the national languages are three regional indigenous ones, Hausa, Igbo \& Yoruba, and then the English 
Language (Davydov, Shapoval, \& Weber, 2018). With the English language being the language of formal education and legislation, and business, locally and internationally. It is worthy of note that Nigeria has over 500 local languages and rich cultures, some of which are gradually going extinct. The minority groups and languages feel maligned even from political roles at the national level, as it appears only persons mostly from two of the major tribes get the big positions and make room for their 'brothers'. Many have little or no sense of belonging towards the Nigerian state. This palpable division has led to and continues to fuel civil unrest and external intrusions to polity, from Western powers and recently, the Asians.

This quandary's root cause as mentioned before can be traced to an identity crisis, not just of Nigeria but Africa, and it is not unrelated to the negative impact of Western domination in years past, globalisation and neocolonialism. As a panacea, this paper leans on Kwasi Wiredu's proposition of Cultural Universals (language communication in particular) as essential for intercultural communication (Fayemi, 2011). Effective intercultural communication, in our context, implies a means for national unity, communication, growth and development.

Findings from empirical reviews validate the assumption that Nigerian Pidgin speaking is more popular compared to the three regional languages, Hausa, Igbo, Yoruba. English language is learnt within formal school structure, thus making it elitist and reducing development and eloquence on a mass scale. Even now, adverts and general announcements from the government are broadcasted in Pidgin to ease the dissemination and understanding of the message. From the foregoing, objective reality indicates that the languages for national communication via the national communication policy appear incapable of effective national communication. However, Pidgin English cuts across all socioeconomic classes, ethnicities and literacy level.

Because of this objective reality, this paper proposes that the pragmatic approach for the government is a review of the National communication policy, creation of a language policy and declaration that the Nigerian Pidgin be included and top the list of languages for National Communication, in the interest of National Unity. The subject matter will be considered by looking at the Nigerian Pidgin English origins and place in National communication. The study also tests the Nigerian Pidgin English against the Spolsky National Language Policy Theory. It also looks at the language's dynamic position as a cultural universal to cater for the nation's multi-ethnic milieu. Finally, the paper considers prospects of Nigerian Pidgin for nation unification, while concluding with a call for a National Language Policy with Nigerian Pidgin as National Language.

\section{Methodology}

This study adopted the discourse analysis methodology and archival research to review constructs to take a conceptual position. Sources of data are online libraries, journal repository platforms like Ebsco and Google scholar. Other sources were books, conference resources, academic journals and relevant magazines.

\section{Theoretical Framework}

\section{Spolsky's National Language Policy Theory on Nigerian Pidgin English}

Spolsky's theory on National Language Policy further aids the argument of this paper. Spolsky (2009) proposes that four common and co-existing forces drive language policies at the national level:

1) National (or ethnic) ideology or claims of identity;

2) the role of English as a global language;

3) A nation's sociolinguistic situation; and

4) An increasing interest in linguistic rights within the social and civil rights framework. (Albury, 2016)

In light Spolsky's theory and the factors or forces that drive national language policies, the Nigerian Pidgin Language has a national identity. It draws some bits of the English language and fuses bits of some of the national languages (i.e. Hausa, Igbo, Yoruba), in understandable contexts. Nigeria's sociolinguistic situation makes the country appear like a multiverse, hence the need for a unifying national language.

The Nigerian Pidgin accommodates all ethnic groups as the dynamism of the language accommodates ethnic variations. It further quells the battle around linguistic rights, politicking around language divides, dousing the label of 'major or minor' and other regional civil entitlement mindsets. This sufficiently positions the Nigerian Pidgin as a cultural universal, and strategically position for adaptation in the National Language Policy. 


\section{Literature Review}

\subsection{National Communication Policy, the Nigerian Pidgin English, Universalist theory}

'Lingua instrumentum regni' is the language policy adopted by European countries (up till the 20th century), and it means that 'language is the instrument of political control' (Bernini, 2013). This policy manifested in the enforcement of English as national communication language is nations dominated by Britain and other western powers.

While there are different theories as to the origin of the Nigerian Pidgin, this paper aligns with the Universalist theory to explain the source of the Nigerian Pidgin. The Universalist Theory is based on the assumption that human persons have the innate capacity and tendency to simplify the language. English was first heard from the Portuguese traders as they traded around the Niger Delta region. Pidgin English thus developed as a contact language from their interaction, collaboration and cohabitation, to ease trade and communication (Ifechelobi \& Ifechelobi, 2015). The Pidgin language has however evolved incorporating bits and pieces of Niger Delta and other Nigerian language inclusions like chai (Igbo), abi (Yoruba), yama-yama (Hausa).

Nigerian Pidgin is described as a contact, and marginal language (Balogun, 2013) used to achieve communication needs in well-defined situations but combining elements of the indigenous language of its speakers (Elugbe \& Omamor, 1991). Ifechelobi \& Ifechelobi (2015) further describe pidginisation as a complex process of sociolinguistics where the indigenous and English language are substrate and superstrate, consecutively.

It is worthy of note that the Nigerian Pidgin has phonological and morphological structure distinct from broken English, which is actually 'bad grammar', a deliberately flawed or failed attempt at speaking the English Language. Case in point is the bad grammar used by Chief Zerubudaya in the old soap opera, 'Village Headmaster'.

In a study that reviewed the challenge of globalisation on the linguistic equilibrium between indigenous and global languages considering the scenarios in Nigeria, India, former USSR and Russia. The common phenomena in the nations studied is a 3-language formula which implied compulsory learning of one's language, a regional language and a global language, which is the English language in this context. Isolating the Nigerian context, the 3-language formula (Hausa, Igbo and Yoruba), plus English were purposed to unify the over 500 ethnic group country. The failed abinitio as strategic implementation and action plans were not in place, particularly the equipping and dispatch of trained language instructors throughout the country (Davydov et al., 2018). These are gaps a language planning and policy ought to have made provision for.

National ideology and identity refer to the set-up of beliefs and principles relevant to a collective psyche that may manifest in a language policy (McConville, 2016). Spolsky's theory then suggests that language policies at the national level are driven by four common and co-existing forces viz national (or ethnic) ideology or claims of identity, the role of English as a global language, a nation's sociolinguistic situation; and an increasing interest in linguistic rights within the human and civil rights framework. (Albury, 2015). Spolsky furthers draws attention to how Arabisation introduced Arabic as an official language, thus impacting National culture and identity. He described the English language as a 'tidal wave' moving into almost every sociolinguistic repertoire' all through the global language ecosystem. But this wave can create tensions between linguistic internationalisation and local language interests implying the tidal wave may be resisted by way of interventions to protect the status or vitality of local languages (McConville, 2016). The tensions predicted by Spolsky are apparent, with ethnic languages and essence of some cultures at the verge of extinction, thus the calls for National Language Planning and Policy in discerning countries.

Language planning is the conscious effort by the government to review the state and propagation of the national language. Any changes or modifications are aimed at modifying the eminence of a language, plus its phonological and or morphological range and functionality (Ifechelobi \& Ifechelobi, 2015). Invariably language planning employs a policy to empower and improve the status of a language. This is an exercise that needs to happen consciously in Nigeria, considering Spolsky's theory of policy development and current socio-political milieu. The above indicates Nigeria as ripe for a National Language Policy, having already the global language, yet a national spread of a dynamic, creative and indigenous language, the Nigerian Pidgin, despite inter-ethnic tensions and politics

\subsection{Nigerian Pidgin as Cultural Universal}

Cultural Universals may be described as social elements that rank as commonalities yet divergent between cultures (Lumen Learning), significantly impacting behaviours and values. Typical examples of the concept include gender roles, society, myth, ritual, aesthetics, cognition, language etc.

This paper is focused on language as a cultural universal because every society has one and is distinguished by 
same (Wiredu, 1995). Languages are imperative in any society, however what the language encompasses and embodies is a matter of exigency (Fayemi, 2011). Language homogenisation beyond merely being a cultural universal is a nation-building tool (Bernini, 2013).

In spite of language imperialism and push to enforce speaking of English language in Nigeria particularly via formal education, mass media (Bernini, 2013) and globalisation, the Nigerian Pidgin language appears as an interethnic code for communicativity where there is no common tongue, with persons from every tribe in the country able to speak it (Balogun, 2013). Further findings from that study indicate over 98\% fluency in Nigerian Pidgin within formal and informal circles, reflecting the language's national identity potential (Balogun, 2013). The Federal Government of Nigeria also implicitly acknowledge this when government campaigns and mass broadcasts are transmitted in Nigerian Pidgin, not to mention the approval of radio and television license for (strictly) Pidgin speaking stations (Akande \& Salami, 2010). This invariably makes Nigerian Pidgin an unofficial lingua franca and national identity marker, distinct in every way, flexible yet understandable by Nigerians regardless of socioeconomic status and literacy level, hence the call to implement same in a National Language policy and revised National Communication policy document.

Wiredu's objective in discussing the cultural universal concept was borne from the African state's quest for identity and meaning as a people (Fayemi, 2011) and this cannot be independent communicativity with an African 'tone'. He emphasised that intercultural differences can be a unification factor.

With human and cultural universals, the excuse of our diversity as Nigerians as cause for continuous division, is no longer an excuse. What needs to be done, is to look and objective realities with sympathetic impartiality, then agree on common norms and thought, communicate, Nigerian Pidgin is our national language for unity and communication. Thus this paper, reviewing the position of Nigerian Pidgin as a cultural universal to foster intercultural communication in Nigeria's multi-ethnic society for effective national communication, unity, development, security and peace.

\subsection{Prospects of Pidgin English Language}

Several scholars have attempted arguments for and against the adoption of Nigerian Pidgin English as a national language to foster effective intercultural and nation communication. Elugbe \& Omamor (1991) recount the bias for Pidgin, its relegation as a make-shift and inferior language, not taking cognisance of the bridge the language builds between different ethnic groups, religious, literacy and socioeconomic class boundaries. Pidgin English is spoken in several West African countries, including Ghana and Sierra Leone. However, the Nigerian Pidgin is better positioned as an indigenous and National Language worthy of being engrained because nobody and everybody in Nigeria owns it. This eliminates the grievance of its acceptance for reasons of being from a 'majority', 'minority' or 'regional' ethnic divide, compared to a scenario in Sierra leone for instance where Creo (Pidgin) was associated with the domineering upper-class, who equally lacked goodwill of the populace, thus the despise for the language.

The call for elevation and adopting Pidgin is not exclusive, considering some countries already use as it as a parliamentary language, particularly Papua New Guinea and Tanzania (Tok, 2012).

Some excuses for not adopting the language include that its restriction of communicative use to informal and verbal situations (Balogun, 2013), the error of mistaking Pidgin for broken English (Ifechelobi \& Ifechelobi, 2015), perception as the language of the illiterate (Akande \& Salami, 2010) and the absence of standard lexical structure for Pidgin.

There are counter-arguments however, including that Nigerian Pidgin is a wholly advanced language equipped with an impressive lexico-semantics and syntax, due its natural evolution characteristic of languages, through contact and modification (Balogun, 2013) even having an online dictionary today (Tok, 2012).

The Nigerian Pidgin is a dynamic language, widespread across the nation with a myriad of fluent speakers who have passed the language across generations, creating history (Ifechelobi \& Ifechelobi, 2015). Thus, in a multiethnic nation-state like Nigeria, any language that can foster national identity and democratic cohesion is imperative (Ogunmodimu, 2015), and Nigerian Pidgin fits the bill for its ethnic neutrality, linguistic flexibility and communicative simplicity.

\section{Discussion and Conclusion}

\subsection{Discussion}

This conceptual paper re-echoes the call for a review of the national communication policy, language planning, 
creation of national language policy and adoption of Nigerian Pidgin English as lingua franca, being a cultural universal in Nigerias' richly multi-cultural and multi-ethnic society.

National communication embodies how people relatively use communicativity to make meaning within and across broader contexts. The quest for National identity has hitherto been elusive for Nigeria, considering the history of western contact and tensions amongst the many ethnic groups herein. This phenomenon was traced to an identity crisis, of Nigeria and a large part of Africa, due to the negative impact of Western domination in years past, globalisation, neo-colonialism and self-doubt in our potential as a people.

Going further, the paper highlights optimising cultural universals, an approach discussed by Kwasi Wiredu while discussing African Philosophy, as imperative in facilitating intercultural and inter-ethnic communications. The cultural universal thus zeroed on by this conceptual paper is language. And for the complex social context of Nigeria, this paper identifies and proposes the adoption of the Nigerian Pidgin English (as lingua franca) to the hot-list for language planning and policy, hitherto non-existent in the country, for the intent of national communication, unity, growth and development.

The tensions predicted by Spolsky are apparent, with ethnic languages and essence at the verge of extinction, thus the calls for National Language Planning and Policy by discerning countries. Instituting a National Language Planning and Policy is a turnkey development; this desire and unique potential for national unity, growth and development in all ramifications are long overdue since Nigeria's independence in 1960.

Nigerian Pidgin speaking is currently more popular compared to the three regional languages, Hausa, Igbo, Yoruba, and English language. This is the case because the English language is learnt within formal school structure, making it elitist and reducing development and eloquence on a mass scale. Government broadcasts and national communication in Nigerian pidgin attest to the proliferation of the language. Clearly indicating the languages for national communication via the national communication policy is incompetent for effective national communication. However, Pidgin English cuts across all socioeconomic classes, ethnicities and literacy level.

\subsection{Conclusion and Recommendations}

In view of objective reality in the Nigerian context and ethnic conflicts, this paper thus proposes a pragmatic approach for the government. This approach is an immediate review of the National communication policy, creation of a language policy and declaration that the Nigerian Pidgin be added and top the list of languages for National Communication. This approach is in the interest of National Unity, security and development.

The perspectives discussed in this paper are key information for the Ministry of Communications, the National Orientation Agency, and the Senate, House of Representatives, the Presidency and other relevant stakeholders, to review and act upon. Communication scholars are also required to help fine-tune the policy document in preparation for strategic implementation.

Considering the Nigerian Pidgin speaking is currently more popular, compared to the three regional languages, Hausa, Igbo, Yoruba, and English language, and does not require the government to send instructors around the country for training others, it is more economical to implement. The language is laced with humour, entertaining and should be introduced to schools, in order to make learning fun, fast and effective.

Government broadcasts and national communication (even in the senate and political houses) in Nigerian pidgin will ease proliferation of the language, connection between the government and the citizens, plus allowing more persons interact with government and each other with concrete understanding and within the communication context.

In essence, the Nigerian Pidgin English may be the key to a unified Nigeria with one sense of purpose and potential for outstanding accomplishments, as one people, in spite of the multi-ethnic reality. Finally, in alignment with the 5th line of the first stanza of the Nigerian National anthem, the adoption of the Nigerian Pidgin English as a national language for unification represents 'the labour of our heroes past not being in vain'; this towards peace and unity; 'so help us God!' (last line of the Nigerian National pledge).

\subsection{Limitations and future directions for research}

This research had some limitations. The study is primarily conceptual and does not delve deeply into the historical and socioeconomic circumstance around the development of the Nigerian Pidgin English. The research also focuses on the Nigerian Pidgin English even though Pidgin English is spoken in other African countries like Sierra Leone.

Future studies can test the concept proposed by this study by conducting compulsory nation-wide surveys in partnership with the Federal Government, to test the acceptability of Pidgin English as a National Language in the 
interest of peace and unity.

\section{References}

Akande, A. T., \& Salami, L. O. (2010). Use and Attitudes towards Nigerian Pidgin English among Nigerian University Students. In R. M. Millar, Marginal Dialects: Scotland, Ireland and Beyond (pp. 70-89). Aberdeen: Forum for Research on the Languages of Scotland and Ireland.

Alberts, M. (2010). National Language and Terminology Policies - A South African Perspective. Lexikos 20, 20, 599-620

Albury, N. J. (2015, March 1). National language policy theory: exploring Spolsky’s model in the case of Iceland. doi:10.1007/s10993-015-9357-z

Balogun, T. A. (2013, July). In defence of Nigerian Pidgin. Journal of Languages and Culture, 4(5), 90-98. doi:10.5897/JLC12.007

BBC News. (2016, November 16). Pidgin-West African Lingua Franca. Retrieved July 6, 2019, from https://www.bbc.com/news/world-africa-38000387

Bernini, A. (2013). Local Languages and Cultural Differences in the Age of GlobaliSation: the Example of Cremonese Dialect. Socialinių mokslų studijos/Societal Studies, 5(1), 87-100. Retrieved July 2019

Bruen, J. (2013). Towards a national policy for languages in. European Journal of Language Policy, 5(1), $99-114$. doi:10.3828/ejlp.2013.5

Davydov, D., Shapoval, A., \& Weber, S. (2018). Linguistic equilibrium with local and world languages: Challenges of globalisation. The World Economy. doi:DOI: 10.1111/twec.12645

East, M., Chung, H., \& Arkinstall, C. (2012). A FAIR GO FOR ALL: A CONTRIBUTION TO THE CALL FOR A NATIONAL LANGUAGES POLICY IN AOTEAROA NEW ZEALAND. New Zealand Studies in Applied Linguistics, 18(2), 05-20. Retrieved July 9, 2019

Elugbe, B. O., \& Omamor, A. P. (1991). Nigerian Pidgin Background and Prospects. English: A Sociolinguistic Approach. Unpublished PhD Dissertation, University of Leeds. Ibadan: Heinemann.

Fayemi, A. K. (2011). A Critique of Cultural Universals and Particulars in Kwasi Wiredu's Philosophy. TRAMES, 15(65/60), 259-276. doi:10.3176/tr.2011.3.03

Gao, X. (2017). Linguistic instrumentalism and national language policy in Mainland China's state print media coverage of the Protecting Cantonese Movement. Chinese Journal of Communication, 10(2), 157-175.

Idang, G. E. (2015). African Culture and Values. Phronimon, 16(2), pp. 97-111.

Ifechelobi, J. N., \& Ifechelobi, C. U. (2015, June). Beyond Barriers: The Changing Status of Nigerian Pidgin. International Journal of Language and Literature, 3(1), 208-216. doi:10.15640/ijll.v3n1a26

Lumen Learning. (n.d.). Cultural Universals. Cultural Anthropology. Retrieved July 12, 2019, from https://courses.lumenlearning.com/culturalanthropology/chapter/cultural-universals/

McConville, M. (2016). Towards a holistic national language policy for Scotland. Glasgow: Association for Scottish Literary Studies.

Ogunmodimu, M. (2015, September). Language Policy in Nigeria: Problems, Prospects and Perspectives. International Journal of Humanities and Social Science, 5(9).

Osoba, J. B., \& Alebiosu, T. A. (2017). Language Preference as a Precursor to Displacement and Extinction in Nigeria: The Roles of English Language and Nigerian Pidgin. Journal of Universal Language, 17(2), 111-143. doi:https://doi.org/10.22425/jul.2016.17.2.111

Sue, W. (2016). Language Policy and Language Planning: From Nationalism to Globalisation (2nd ed.).

The Nation Online. (2016, July 8). Case for Pidgin English as Lingua Franca. The Nation Online Newspaper. Retrieved July 9, 2019, from https://thenationonlineng.net/case-pidgin-english-lingua-franca/

Tok, P. (2012). Pidgin-English Online Dictionary. Retrieved July 13, 2019, from www.calibercreations.com/pisin Wiredu, K. (1995). Are there Cultural Universals? The Monist: An International Journal of General Philosophy, 78(1), 52-64. Retrieved July 12, 2019, from www.jstor.org 